\title{
Aortic Valve Repair: An Evolving Space in Cardiac Surgery
}

\author{
Mario Petrou \\ Trust, Sydney Street, London SW3 6NP \\ *Author for correspondence: \\ Email: m.petrou@rbht.nhs.uk \\ Received date: February 13, 2020 \\ Accepted date: February 24, 2020 \\ Publication date: March 02, 2020
}

(2) Foundation

\section{Commentary}

The surgical management of pure aortic regurgitation (AR) continues to evolve and the choice of operation depends on several factors including, the patho-anatomy of the aortic valve and root, patient characteristics and surgical expertise. The absence of an ideal biological or mechanical prosthesis historically stimulated the development of innovative valve-conserving techniques. Early pioneers invented the now established valve sparing aortic root replacement using the remodelling and re-implantation techniques $[1,2]$ which focus on the geometrical correction of the aortic root and restoration of the normal alignment of the aortic valve apparatus to eliminate secondary AR. In the last 10 years or so however, some surgeons have pushed the envelope even further by introducing novel approaches to address primary AR using cusp repair techniques and associated annuloplasty [3-5]. This concept is analogous to more established mitral valve repair techniques which are now refined, reproducible and associated with excellent clinical outcomes. Indeed, it could be said that the current status of aortic valve repair surgery stands where mitral valve repair was some 35 years ago i.e. the preserve of only a hand-full of surgeons working in high-volume centres with a strong innovative ethos.

The general principles of valve repair (mitral, tricuspid and aortic) are well established and start with high-quality TOE analysis to define the mechanism of the regurgitation which in turn guides the strategy for surgical correction. This point cannot be overstated as it forms part of the sine qua non for achieving excellent results. Thus, the availability of an expert in surgical echocardiography who works closely with the surgeon as part of the complex aortic team is essential. The surgeon correlates the echo images with the intraoperative findings before proceeding with the repair in a logical manner. The "tool-box approach" for aortic valve repair is probably the most useful and encompasses a variety of well described techniques incl. free-edge plication, margin reinforcement, shaving of the hypertrophied noduli of Aranti, raphe release, limited decalcification, sub-commissural annuloplasty, internal or external annuloplasty ring implantation and rarely, cusp augmentation with autologous pericardium [6]. Tissue quality as assessed by the surgeon is also an important consideration and, as with mitral repair, it is better to have an excess of tissue which allows greater versatility of repair techniques available to the surgeon. By contrast, leaflet retraction and fibrotic shrinkage is a more challenging problem and attempts to augment these cusps using autologous pericardium are generally associated with sub-optimal long-term outcomes.

Young patients ( $<55$ years) with pure AR seeking a biological solution should be informed about the option of aortic valve repair. However, it is important to emphasise that modern generation bioprostheses perform pretty well in the modern era with good 10-15 years durability, particularly in the older age group. Furthermore, recent innovations in valve design e.g. the Edwards Inspiris (Resilia) bioprosthesis promise to offer even longer freedom from re-operation and 'future-proof' the patient for easier valve-in-valve TAVI [7]. The results of aortic valve repair surgery are generally reported by the few major European centres which have a relatively high volume experience. The Belgian group for example report very good early and late results but emphasise the importance of the surgical learning curve [8]. The question however remains as to whether a good aortic valve repair is as durable (or even superior) as a bioprosthetic valve substitute? We have no data available to answer this and help guide the consent process since such a head-to-head trial has not yet been done. In the meantime, it is reasonable to offer AV repair to patients with pure AR who require a biological solution for various reasons providing they are under the care of an experienced aortic team with a recognised interest in valve conserving techniques and robust consent processes. Indeed, this currently forms part of the class I recommendation in the ESC/EACTS [9] and AHA/ACC [10] guidelines.

Our group recently published an early UK experience on a series of patients with pure AR who were treated with a combination aortic root remodelling and/or isolated cusp repair. A variety of techniques were employed with excellent early results. However, the freedom from re-operation at 8 years was only $88.15 \% \pm 1.51 \%$ in this relatively small group of patients. We therefore remain mindful about sounding a note of caution but also remain confident that long-term outcomes may improve with better patient selection, increased experience and incremental refinements to techniques. Aortic valve repair surgery continues to evolve in cardiac surgery and concentrating the limited experience to specialist centres is generally recommended.

\section{References}

1. Birks EJ, Webb C, Child A, et al. Early and long-term results of a valve-sparing operation for Marfan syndrome. Circulation. 1999;100:29-35.

2. David TE, Feindel CM. An aortic valve-sparing operation for patients with 
aortic incompetence and aneurysm of the ascending aorta. J Thorac Cardiovasc Surg 1992;103:617-621.

3. El Khoury, Gebrine. Principles of aortic valve repair. J Thorac Cardiovasc Surg. 2013;145:26-29

4. Schäfers HJ, Bierbach B, Aicher D. A new approach to the assessment of aortic cusp geometry. J Thorac Cardiovasc Surg. 2006;132:436-438

5. Greco R, Muretti M, Jin X, et al. Aortic valve repair techniques: An early UK experience. Open Heart. 2019;6:e001107.

6. Emmanuel L, Laurent de K. Aortic valve repair techniques: State of the art. Eur J Cardiothorac Surg. 2018;53:1101-1107.
7. Puskas JD, Bavaria JE, Svensson LG, et al. COMMENCE Trial Investigators. The COMMENCE trial: 2-year outcomes with an aortic bioprosthesis with RESILIA tissue. Eur J Cardiothorac Surg. 2017;52:432-439.

8. Malas T, Saczkowski R, Sohmer B, et al. Is aortic valve repair reproducible? Analysis of the learning curve for aortic valve repair. Can J Cardiol. 2015;31:1497.e15-22.

9. Falk V, Baumgartner H, Bax JJ, et al. ESC Scientific Document Group. 2017 ESC/EACTS Guidelines for the management of valvular heart disease. Eur J Cardiothorac Surg. 2017;52:616-664.

10. Nishimura RA, Otto CM, Bonow RO, et al. 2017 AHA/ACC Focused Update of the 2014 AHA/ACC Guideline for the Management of Patients with Valvular Heart Disease: A Report of the American College of Cardiology/ American Heart Association Task Force on Clinical Practice Guidelines. J Am Coll Cardiol. 2017;11:252-289. 